Int. J. Dev. Biol. 61: 149-157 (2017)

doi: $10.1387 / \mathrm{ijdb} .160346 \mathrm{gl}$

\title{
The not-so-long history of zebrafish research in Israel
}

\author{
JANNA BLECHMAN ${ }^{1}$, GIL LEVKOWITZ*,1 and YOAV GOTHILF*,2 \\ ${ }^{1}$ Department of Molecular Cell Biology, The Weizmann Institute of Science, Rehovot, Israel and \\ ${ }^{2}$ Department of Neurobiology, The George S. Wise Faculty of Life Sciences and Sagol School of Neuroscience, \\ Tel-Aviv University, Tel Aviv, Israel
}

\begin{abstract}
The zebrafish has become a model of choice in fundamental and applied life sciences and is widely used in various fields of biomedical research as a human disease model for cancer, metabolic and neurodegenerative diseases, and regenerative medicine. The transparency of the zebrafish embryo allows real-time visualization of the development and morphogenesis of practically all of its tissues and organs. Zebrafish are amenable to genetic manipulation, for which innovative genetic and molecular techniques are constantly being introduced. These include the study of gene function and regulation using gene knockdown, knockout and knock-in, as well as transgenesis and tissue-specific genetic perturbations. Complementing this genetic toolbox, the zebrafish exhibits measurable behavioral and hormonal responses already at the larval stages, providing a viable vertebrate animal model for high-throughput drug screening and chemical genetics. With the available tools of the genomic era and the abundance of disease-associated human genes yet to be explored, the zebrafish model is becoming the preferred choice in many studies. Its advantages and potential are being increasingly recognized within the Israeli scientific community, and its use as a model system for basic and applied science has expanded in Israel in recent years. Since the first zebrafish-focused laboratory was introduced at Tel Aviv University 16 years ago, seven more zebrafish-centric research groups have been established, along with more than two dozen academic research groups and three bio-medical companies that are now utilizing this model.
\end{abstract}

KEY WORDS: model organism, genetics, drug discovery, biomedical, human disease model, hypothalamus, vascular biology, circadian clocks, sleep, stress, social affiliation, aquaculture

\section{A bit of history}

The zebrafish (Danio rerio) has become a well-accepted model system for addressing a wide spectrum of biological questions from the cellular to the whole organism level. The use of zebrafish as a genetic model was pioneered by George Streisinger in the 1960s at the University of Oregon [reviewed in (Grunwald and Eisen, 2002)]. Streisinger introduced a vertebrate model organism that is simpler than the mouse and then showed that it could be genetically manipulated (Streisinger et al., 1981). A huge step forward in the field was taken in the early 1990s by Christiane Nusslein-Volhard in Germany and Wolfgang Driever and Mark Fishman in the USA, who performed two genetic screens that yielded thousands of developmental mutants (Driever et al., 1996, Haffter et al., 1996). Another major advance in the development of the world zebrafish community was initiated by whole zebrafish genome sequencing, which was started at the Wellcome Trust Sanger Institute, UK, in 2001. The heightened appreciation of a new model organism had become evident by the end of the $20^{\text {th }}$ century, leading to an astonishing 100-fold increase in the number of publications from the mid-1990s to present. About $70 \%$ of genes and more than $80 \%$ of disease-associated genes are shared by humans and zebrafish, rendering this rapidly reproducing and easily bred transparent organism a preferred model for addressing basic questions of developmental biology, physiology, and pathology. Zebrafish research is an extensively growing field, with $\sim 1,000$ zebrafishfocused laboratories worldwide. Although the Israeli zebrafish research community is relatively small, new research groups are established almost every year. Israeli zebrafish research encompasses diverse topics, inculding nervous system development and function, neurodegeneration, cardiovascular development and function, endocrinology, and cancer.

\footnotetext{
*Address correspondence to: Gil Levkowitz. Department of Molecular Cell Biology, The Weizmann Institute of Science, 7610001 Rehovot, Israel. Fax: +972-8-934-4125. Tel: +972-8-934-4125. E-mail: gil.levkowitz@weizmann.ac.il - web: http://www.weizmann.ac.il/mcb/GLevkowitz (iD) http://orcid.org/0000-0002-3896-1881 - or

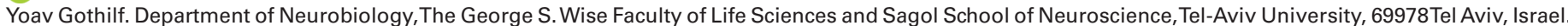
Tel/fax: 972-3-6406329 . E-mail: yoavg@tauex.tau.ac.il - web: http://gothilflab.wix.com/gothilflab iD http://orcid.org/0000-0002-6054-4128
}

Accepted: 5 October, 2016.

ISSN: Online 1696-3547, Print 0214-6282 


\section{Early zebrafish days in Israel}

During the 1990s, the desire to visualize 3- and 4-dimensional processes in developing organisms in vivo led to the initiation of zebrafish research at the Weizmann Institute of Science. At that time Benny Geiger and Tziki Kam were looking for embryos that were transparent and easy to work with, and chose to focus on developing zebrafish embryos. Long-term interactions between Geiger and Jim Weston from Eugene, Oregon, provided friendly access to the cradle of zebrafish research in Eugene as well as crucial help and guidance from the zebrafish experts in Eugene, including Weston, Judith Eisen, Charles Kimmel, Monte Westerfield, and others. Benny Geiger and Tziki Kam, together with their graduate student Sigal Bitzur, used standard aquaria and fish, which were purchased from a local pet shop. Breeding zebrafish was quite a challenge for these researchers, who had worked mostly with cultured adherent cells. With hands-on help from Jim Weston and Judith Eisen, who visited the Weizmann Institute, the small 'fish facility' started to yield embryos and amazing images of adherenstype junctions at various stages of early embryo development (Fig. 1). Anat Yarden and Eli Zamir (then an MSc student) joined the lab, with an interest in studying cell-cycle regulation during early stages of zebrafish embryonic development, and the small fish enterprise grew even further. The studies expanded from looking into cell-cell adhesion during embryonic development (Bitzur et al., 1994) to monitoring the dynamic cell-division patterns (Zamir et al., 1997) and molecules involved in cell-cycle regulation (Yarden and Geiger, 1996, Yarden et al., 1995).

\section{The $3^{\text {rd }}$ millennium}

In 2001, Yoav Gothilf established the first zebrafish-centric laboratory at Tel Aviv University. The zebrafish colony initially used for Gothilf's research comprised the pineal-specific transgenic zebrafish lines that he had developed at the National Institutes of Health (NIH), Maryland, in collaboration with Reiko Toyama, Igor Dawid and David Klein (Gothilf et al., 2002). The lines (Fig. 2) were shipped to Israel on a commercial flight, together with Gothilf. The second zebrafish lab was established by Gil Levkowitz in 2004 at the Weizmann Institute of Science in Rehovot. Levkowitz airmailed some catecholaminergic-deficient mutant fish (Levkowitz et al., 2003) that he had studied during his postdoctoral research in the USA to the 'fish-sitter' (Gothilf's lab) at Tel-Aviv, where the

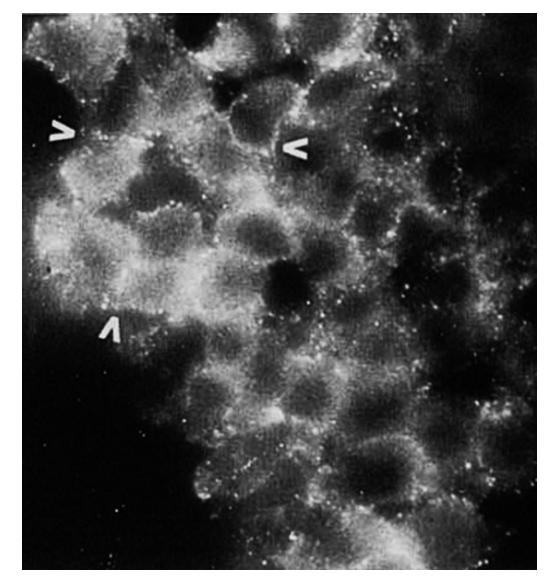

Fig. 1. Localization of zebrafish $\mathbf{N}$-cadherin, showing the organization of cell-cell adhesions during epiboly.

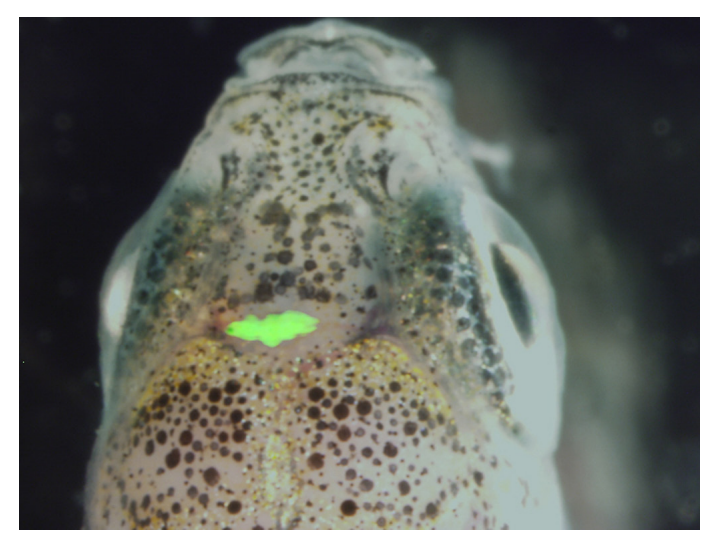

Fig. 2. Transgenic zebrafish expressing enhanced green fluorescent protein in the pineal gland under control of the pineal-specific aanat2 promoter.

immigrant fish awaited their relocation to their permanent home in the Weizmann Institute.

With time, additional laboratories world wide adopted the zebrafish as their primary model organism and more Israeli postdoctoral fellows chose to conduct their research in those labs. In 2008, in order to attract these promising young zebrafish investigators, Gothilf and Levkowitz organized the first Israeli Zebrafish Meeting, entitled 'Zebrafish as a Model Organism: New Horizon for Basic and Applied Research in Israel.' This one-day meeting, held at Tel Aviv University, attracted considerable attention of non-zebrafish scientists. In particular, it introduced the original studies using the zebrafish model, which had been performed by two young international 'zebrafish' Israeli postdoc researchers, Karina Yaniv and Lior Appelbaum, who later established their own labs in Israel. The tradition continued, as the Israeli zebrafish community continued to expand. The $2^{\text {nd }}$ Israeli Meeting on Zebrafish as a Model Organism for Biomedical Studies, held in 2010, already included Limor Ziv, who had returned from a postdoc fellowship at University of California, San Francisco (UCSF) to work with Gideon Rechavi at the Cancer Research Center, Sheba Medical Center, Tel Hashomer, and Adi Inbal and Karina Yaniv as independent zebrafish investigators running their labs at the Hebrew University of Jerusalem and the Weizmann Institute of Science, respectively. The $3^{\text {rd }}$ Zebrafish Meeting was held at the Weizmann Institute in 2012 and was organized by Yaniv and Appelbaum, who was already an Assistant Professor at Bar-llan University. This meeting was attended by two new young Israeli zebrafish investigators: Alon Daya from the School of Marine Sciences of the Ruppin Academic Center in Michmoret, and Niva Russek-Blum, who had just been appointed as a scientist at the Dead Sea and Arava Science Center (under the auspices of Ben-Gurion University of the Negev), and who is now literally raising fish in the desert. The latest meeting, held in 2015, included two new zebrafish investigators: David Karasikfrom Bar-Ilan University Faculty of Medicine in the Galilee, and Ramon Birnbaum from Ben-Gurion University of the Negev.

Overall, Israeli zebrafish meetings are now held every other year, featuring keynote lectures presented by renowned international zebrafish investigators. Past keynote speakers have included Wolfgang Driever (University of Freiburg), Marnie Halpern (Carnegie Institution for Science), Florian Engert (Harvard Medical School), Franscisco Quintana (Harvard Medical School), Didier Stainer (Max Planck Institute for Heart and Lung Research), and 
Randall Peterson (Harvard Medical School). The Israeli zebrafish research community is now being recognized as a tour de force in the international field, and as a token of this appreciation, the $3^{\text {rd }}$ European Zebrafish Principal Investigators Meeting (EZPM) was held in 2014 at the lowest place in the world, the desert oasis of Ein Gedi on the shores of the Dead Sea.

\section{A bit of science}

Eight zebrafish-focused laboratories are currently operating in the Israeli academic community. Furthermore, recognizing the potential of this model system, additional Israeli research groups have started using the zebrafish model to extend their research. Dedicated to expanding the use of zebrafish as a model, the eight zebrafish-centric laboratories have been assisting others to initiate research in zebrafish. This research includes such diverse topics as sensory system functions, brain development and neurodegeneration, RNA complexity, gene regulation, and the function of disease-related genes. In the following we briefly describe published and ongoing research projects performed by Israeli zebrafish labs.

\section{Brain development and function}

\section{Forebrain and eye development}

Adi Inbal at the Hebrew University of Jerusalem is exploring the role of the transcription factor Six 3 in early forebrain and eye development. Mutations in the human $S I X 3$ gene are a cause of holoprosencephaly, the most common forebrain malformation, which can result in a number of eye malformations including anophthalmia, microphthalmia and coloboma. In particular, the Inbal lab has identified the roles of Six3 in the formation of specific forebrain structures, as well as in optic nerve morphogenesis (Samuel et al., 2016). Inbal's lab has also investigated new roles for Six3 in regulating the timing of retinal neurogenesis. Genes associated with early onset of blindness, known as Leber's congenital amaurosis, have also been investigated in zebrafish by Hadas Stiebel-Kalish, an ophthalmologist at the Rabin Medical Center, Petach Tikva (Rainy et al., 2016, Stiebel-Kalish et al., 2012).

The hypothalamus is a prominent part of the forebrain that regulates the body's homeostasis by controlling hormonal and behavioral functions. Gil Levkowitz's group at the Weizmann Institute was among the first to utilize zebrafish as a vertebrate model organism to study the development and function of the various neurons that comprise the hypothalamus (Biran et al., 2015). They identified hypothalamic progenitors and characterized the neuroanatomy of the hypothalamic neurons in zebrafish (Borodovsky et al., 2009, Russek-Blum et al., 2009), as well as the signaling pathways involved in spatio-temporal coordination of hypothalamic cell fates (Blechman et al., 2007) and the molecular mechanisms controlling the precise number of hypothalamic neurons (RussekBlum et al., 2008). Lior Appelbaum's lab at Bar-llan University has been studying specific hypothalamic neuronal circuits involved in energy metabolism and behavioral-state transitions. His group characterized the hypothalamic neuronal networks of neurotensin and hypocretin (Levitas-Djerbi et al., 2015). Appelbaum's lab has also identified and characterized novel sleep genes and profiled the transcriptome of the hypocretin/orexin (Hcrt) neurons, which regulate the sleep-wake cycle (Yelin-Bekerman et al., 2015). Appelbaum's findings have established the zebrafish as a model for studying the role of these neuronal circuits in the regulation of feeding, sleep, and reward.

\section{Neuroendocrine system}

The neuroendocrine system, and in particular the hypothalamopituitary system that mediates the secretion of various neurohormones into the blood circulation and through which the brain affects peripheral physiology, has been extensively studied by several labs. Yoav Gothilf's lab, in collaboration with Yonathan Zohar's group at the University of Maryland, has studied the developmental migration of gonadotropin-releasing hormone $(\mathrm{GnRH})$ neurons, key regulators of reproduction in all vertebrates (Abraham et al., 2009, Abraham et al., 2010, Abraham et al., 2008, Palevitch et al., 2007). The correct course of migration and positioning of these neurons is crucial for reproductive fitness, and its impairment results in the human reproductive failure known as congenital hypogonadotropic hypogonadism $(\mathrm{CHH})$. These findings were then extended to functional studies of genes involved in regulation of the developmental migration of $\mathrm{GnRH}$ neurons and in $\mathrm{CHH}$ (Bassi et al., 2016, Palevitch et al., 2009, Palevitch et al., 2010). The $\mathrm{GnRH}$ sytem and its targets in the pituitary gland, luteinizing hormone ( $\mathrm{LH})$ and follicle-stimulating hormone (FSH), have long been among the main topics of interest of Berta Levavi-Sivan's research group at the Faculty of Agriculture, Food and Environment, of the Hebrew University of Jerusalem in Rehovot. Levavi-Sivan's lab is focusing on reproductive physiology and endocrinology in various fish species. They have developed and used transgenic zebrafish FSH and LH reporter lines (Fig. 3) to demonstrate that $\mathrm{FSH}$ and $\mathrm{LH}$ cell populations differ in their distribution, ultrastructure of hormonal packing, proximity to blood vessels, and $\mathrm{GnRH}$ signaling (Golan et al., 2014). These differences form the basis for their differential regulation and secretion patterns, and provide valuable insight into the evolution of the hypothalamic-pituitary axis in vertebrates (Golan et al., 2016, Golan et al., 2015). With the aim of understanding the hypothalamic regulation of food consumption, recent work at the Gothilf laboratory, in collaboration with Roger Cone, University of Michigan, focuses on the development and function of agouti-related peptide (AgRP) neurons in the zebrafish

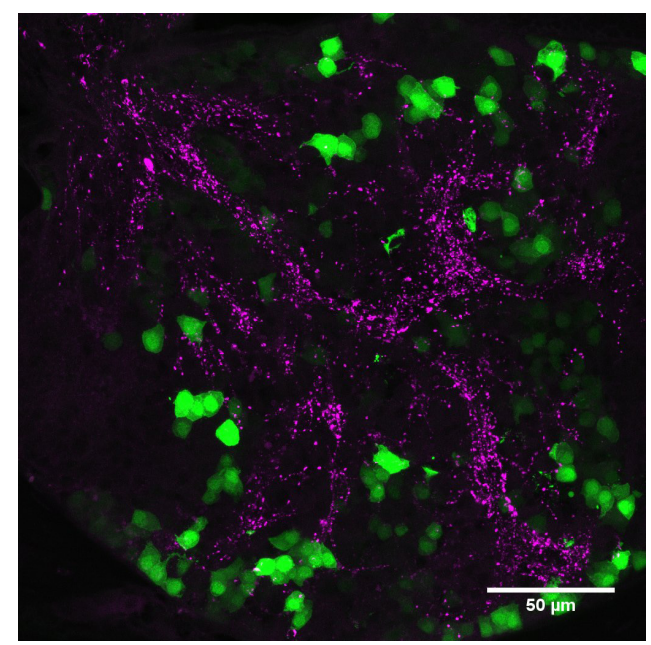

Fig. 3. Transgenic zebrafish reveal the architecture of gonadotropinreleasing hormone ( $\mathrm{GnRH}$ ) fiber-gonadotrope cell interaction in the pituitary. GnRH3 fibers (magenta) arborize within the zebrafish pituitary, forming varicosities adjacent to FSH gonadotropes (green). 


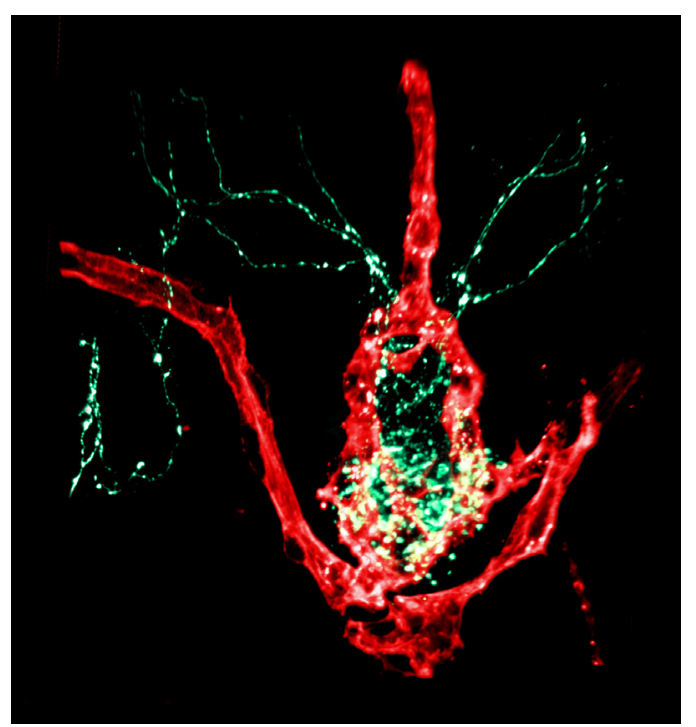

Fig. 4. Transgenic zebrafish expressing oxytocin (green) and vascular endothelial (red) reporters reveal the structure of the zebrafish hypothalamo-neurohypophyseal neurovascular interface.

hypothalamus (Shainer et al., 2017).

The Levkowitz lab is studying the morphogenesis and function of the hypothalamo-neurohypophyseal system, an interface through which the brain regulates body homeostasis by releasing the hypothalamic neurohormones, oxytocin and arginine-vasopressin, directly into the circulation. Oxytocinergic neurons have an ancient role in stress and in social and reproductive behaviors (Wircer et al., 2016). Their work has demonstrated how hypothalamic axons contact neuroendocrine blood capillaries to form the hypothalamoneurohypophyseal neuro-vascular interface (Fig. 4) (Gutnick et al., 2011).

\section{Biological clock and sleep}

The circadian clock system is the main focus of the Gothilf laboratory at Tel Aviv University. Gothilf's interest in this system began during postdoc training in David Klein's lab at $\mathrm{NIH}$, with investigation of the rhythmic generation of the melatonin hormonal signal by the pineal gland, a central component of the circadian clock in all vertebrates. Gothilf's lab identified a regulatory mechanism that simultaneously controls pineal-specific and rhythmic gene expression (Appelbaum et al., 2005, Appelbaum and Gothilf, 2006, Appelbaum et al., 2004). Further research has revealed new players in the circadian clockwork that connect the core molecular clock with downstream physiology of the pineal gland and with rhythmic behavior (Alon et al., 2009, Tovin et al., 2012). Gothilf's findings on the functional development of the pineal gland circadian clock (Ziv and Gothilf, 2006, Ziv et al., 2005) have led to an ongoing long-term partnership with the Foulkes lab at Karlsruhe Institute of Technology (KIT), Germany, which concentrates on how the circadian clock system is entrained by light. This research avenue was extended to describe the entire light-induced transcriptome of the zebrafish pineal gland, resulting in functional analysis of light-induced genes and their molecular and behavioral consequences (Ben-Moshe et al., 2014a). A major current and future focus in Gothilf's lab is the importance of the central clock within the pineal gland and other brain centers, and of peripheral clocks, for the functioning of the entire circadian timing system (Ben-Moshe et al., 2016).

A principal target of the circadian clock system is the regulation of the sleep-wake cycle. Lior Appelbaum's group is investigating the mechanisms underlying the sleep disorder narcolepsy, which is associated with Hcrt neuron deficiency. Focusing on hypocretin neurons, which are regulators of the sleep-wake cycle, they showed that ablation of hypocretin neurons alters the behavioral response to external stimuli in zebrafish, further establishing the zebrafish as a model for sleep-related disorders (Elbaz et al., 2012). They next identified a novel set of hypocretin neuron-specific genes in zebrafish, including the voltage-gated potassium channel Kcnh4a gene. Mutant $k c n h 4 a$ larvae were found to exhibit reduced sleep time and consolidation, specifically during the night (Yelin-Bekerman et al., 2015).

During his postdoctoral research at Stanford University, Appelbaum found that specific hypocretin circuits exhibit rhythmic structural synaptic plasticity in a circadian and sleep-dependent manner (Appelbaum et al., 2010, Elbaz et al., 2013). In a follow-up study, the Appelbaum lab has identified and characterized new synaptic proteins, such as NPTX2a, which are required for rhythmic structural synaptic plasticity (Elbaz et al., 2015). Their work establishes the zebrafish as a model to study structural synaptic plasticity in intact behaving animals (Fig. 5).

\section{Stress and social behaviors}

The Levkowitz lab has demonstrated a novel gene regulatory mechanism underlying hypothalamic neuronal adaptation to stress (Amir-Zilberstein et al., 2012). They noted that the expression of several 'developmental' transcription factors is maintained in terminally differentiated corticotropin-releasing hormone (CRH) neurons, whose activity is critical for animal adaptation to emotional and physiological challenges. Using various stress paradigms they revealed that activation and termination of the stress response are modulated by activity-dependent alternative splicing of the G-protein-coupled receptor PAC1 (Amir-Zilberstein et al., 2012, Blechman and Levkowitz, 2013). Having established and developed genetic tools to track and manipulate oxytocinergic neurons of the zebrafish, another current focus of the Levkowitz lab is to elucidate the role of specific oxytocinergic circuits in animal behavior and physiology (Blechman et al., 2011, Wircer et al., 2016). Recently, they have been mapping the complete set of axonal connections

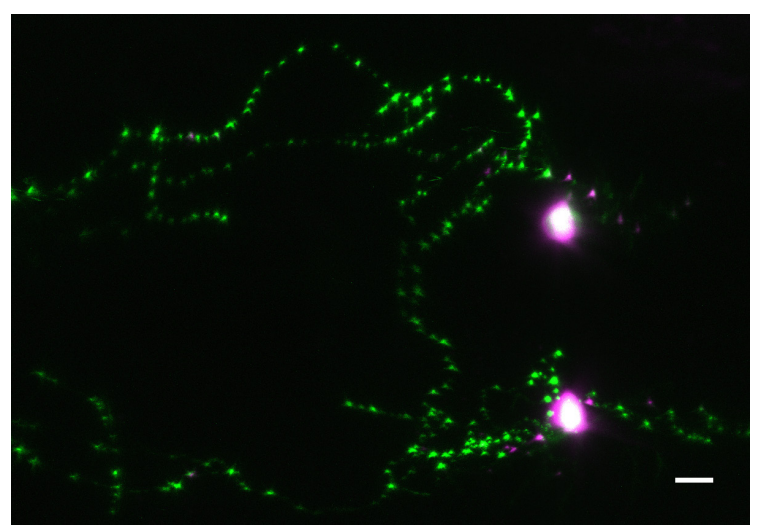

Fig. 5. Live imaging of presynaptic (green) and postsynaptic (magenta) vesicles in axons and dendrites, respectively, of hypocretin/orexin neurons in each hypothalamic hemisphere. 
made by each oxytocinergic neuron and associated abnormal social behavior with developmental alterations in specific OXT-ergic circuits (Wircer et al., 2017). Understanding these processes is especially important, as developmental impairments of hypothalamic neuronal circuits are associated with neurological disorders such as depression, chronic stress and autism. Limor Ziv, at the Cancer Research Center, Sheba Medical Center, has been continuing her previous studies as a postdoc fellow with Herwig Baier (Ziv et al., 2013) and developing further methodologies for the use of adult zebrafish as a model to study depressive disorders.

\section{Microglia and inflammatory diseases}

Niva Russek-Blum carries out research on zebrafish at the Dead Sea and Arava Science Center, located deep in the Arava Valley, close to the Jordanian border. In collaboration with Alon Monsonego from Ben-Gurion University, the Russek-Blum lab is studying the impact of inflammatory responses in ischemic stroke and neurodegenerative pathologies, such as Alzheimer's and Parkinson's diseases, amyotrophic lateral sclerosis (ALS), and multiple sclerosis. Her lab utilizes the zebrafish model to track microglial cells during early brain development and in states of ischemia and neurodegeneration. In collaboration with Rivki Ofir at the Dead Sea and Arava Science Center, who has built a library of materials extracted from desert plants, Russek-Blum is performing a highthroughput behavioral and morphologic screening of zebrafish for the evaluation of potential ALS therapeutics.

\section{Genetic neuropsychiatric disorders}

The X-linked psychomotor retardation Allan-Herndon-Dudley syndrome (AHDS) is associated with mutations in the thyroid hormone (TH) monocarboxylate transporter 8 (mct8). Appelbaum's lab established azebrafish model of mct8 deficiency using targeted gene editing. Mutant mct8 larvae were found to exhibit behavioral deficiencies that are associated with altered expression of myelin-related genes and neuron-specific deficiencies in circuit formation (Vatine et al., 2013, Zada et al., 2014). These findings suggest a mechanism by which MCT8 regulates neural circuit assembly, ultimately mediating sensory and motor control of behavioral performance. Another genetic brain disorder for which Appelbaum's group has proposed new mechanisms is the fragile X syndrome (FXS), where the lack of fragile $X$ mental retardation protein (FMRP), encoded by the fmr1 gene, leads to increased synaptic protein translation. They found that fmr1-mutant fish exhibit increased axonal branching and synaptic density, which are associated with hyperlocomotor activity (Shamay-Ramot et al., 2015). In collaboration with the lab of Erez Levanon at Bar-Ilan University, they have further shown that FMRP regulates the activity of the enzyme adenosine deaminase acting on RNA (ADAR) and the levels of RNA editing primarily in synaptic genes. These results suggest that altered RNA editing in synaptic genes may affect synaptic function and ultimately also behavior in FXS.

\section{Vascular and lymphatic systems}

\section{Lymphatic development}

Karina Yaniv's lab at the Weizmann Institute has addressed the developmental, molecular, and cellular underpinnings of blood and lymphatic vessel formation. Yaniv's studies have been recognized primarily for their novel insights into the cellular origins of late- forming vessels, including the lymphatic endothelium (Nicenboim et al., 2015, Semo et al., 2016). While investigating the origins of the lymphatic endothelium in developing zebrafish embryos, Yaniv's group traced lymphatic progenitor cells to unexpected new origins, thereby challenging the current paradigm of a 'strict' venous origin for lymphatic vessels (Nicenboim et al., 2015). They have identified a novel signaling mechanism controlling lymphatic cell specification and shown that this signaling mechanism also promotes the 'angioblast-to-lymphatic' transition in human embryonic stem cells, suggesting that this process is evolutionarily conserved (Nicenboim et al., 2015).

\section{Organ-specific vessel formation}

Although it is widely accepted that blood vessels show features specific to the organ they vascularize, it is not yet understood how organ-specific vessels arise during embryonic development, nor what molecular mechanisms regulate their formation. In the course of analyzing the formation of the gastrointestinal tract vasculature during embryonic development, the Yaniv lab has discovered a common origin for vessels of the liver, pancreas, and intestines in the zebrafish embryo, and has provided a thorough characterization of the molecular signals underlying their specification and assembly (Hen et al., 2015). Vascularization of the heart can be seen in Fig. 6.

Atissue-specific vascularization of immense medical importance is that of the eye. While studying the interactions between developing eye tissues and ocular vasculature, the Inbal lab discovered that mutation in the Imo2 gene leads to an abnormally enlarged hyaloid vein, which interferes with optic fissure closure and thereby causes coloboma, thus identifying a new mechanism that could lead to this eye malformation (Weiss et al., 2012). They subsequently analyzed the development of superficial ocular vessels and identified their origins, growth dynamics, and acquisition of arterial and venous identities, and thus provided a basis for current studies aimed at identifying the underlying molecular mechanisms determining eye vascularization (Kaufman et al., 2015). The Inbal lab is also studying the non-metabolic effects of forming vasculature on retinal development. Initial studies using cloche mutants support the idea that normal blood-vessel development is required for proper retinal neurogenesis (Dhakal et al., 2015).

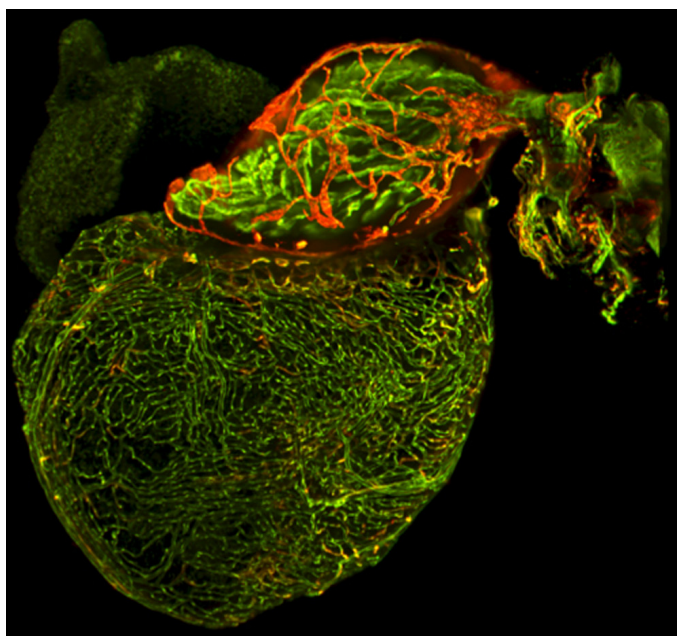

Fig. 6. Light-sheet fluorescence microscopy image of the adult zebrafish heart with blood and lymphatic vessels highlighted in green and red, respectively. 


\section{Neurovascular interaction}

The Levkowitz lab is seeking to elucidate the cellular and molecular mechanisms by which the hypothalamus controls neuroendocrine body function. A primary current research direction is that of studying the assembly and maintenance of the hypothalamoneurohypophyseal neuroendocrine interface between oxytocinergic neurons and the neurohypophyseal vasculature through which oxytocin is released into the general circulation. They showed that neurovascular contact between hypothalamic axonal termini and neurohypophyseal blood capillaries is regulated by local release of the neuropeptide oxytocin from developing nerve termini of the hypothalamo-neurohypophyseal system (Gutnick et al., 2011, Gutnick and Levkowitz, 2012).

\section{Lipids and angiogenesis}

The interaction between endothelial cells and lipoproteins has direct relevance for atherosclerosis, thrombosis, and cardiovascular disease. During her postdoctoral research with Brant Weinstein at the NIH, Karina Yaniv identified a mutation, stalactite (st/), in the gene that encodes the microsomal triglyceride transfer protein (mtp), which is involved in the biosynthesis of apolipoprotein B (ApoB) containing lipoproteins. After establishing her own lab at the Weizmann Institute, Yaniv's group utilized the mtp mutant to demonstrate a link between metabolic cues and blood vessel growth (Avraham-Davidi etal., 2012, Avraham-Davidi etal., 2013). The Yaniv lab recently extended these findings to disease states of angiogenesis and, importantly, has uncovered new roles for apolipoproteins as inhibitors of tumor angiogenesis.

\section{Erythropoesis}

In seeking to elucidate the role of activity-dependent neuroprotective protein (ADNP) and its homologue ADNP2 in neurotube closure and brain formation, Illana Gozes and her group at the Sackler Faculty of Medicine, Tel Aviv University, used the zebrafish model for knock-down experiments. An unexpected result of their study was that the zebrafish morphants were found to lack blood cells (Dresner et al., 2012). This led to the discovery of an ancestral and conserved role for the ADNP protein family in the maturation and differentiation of the erythroid lineage, associated with direct regulation of $\beta$-globin expression.

\section{Musculoskeletal system}

\section{Bone development and structure}

Several 'non-zebrafish' labs at the Weizmann Institute have recognized the value of the zebrafish model in studying bone development and structure. Elazar Zelzer's lab has employed zebrafish and mouse to uncover the role of muscle-induced mechanical loads in regulating chondrocyte intercalation. They found abnormal pharyngeal cartilage morphology in both chemically and genetically paralyzed embryos, demonstrating the importance of muscle contraction for zebrafish skeletal development (Schwartz et al., 2012).

Lia Addadi and Steve Weiner at the Weizmann Institute are studying mechanisms of bone formation utilizing the caudal fin of adult and larval zebrafish, a simple bone model system in which mineralization is temporally and spatially resolved. They have shown that mineral deposition of amorphous calcium phosphate may be a precursor phase that later transforms into the mature crystalline mineral of bone, namely carbonated hydroxylapatite (Mahamid et al., 2008). Using synchrotron microbeam x-ray diffraction and small-angle scattering, combined with cryoscanning electron microscopy, they further demonstrated that new mineral is delivered and deposited as packages of amorphous calcium phosphate nanospheres, which transform into platelets of crystalline mineral (Mahamid et al., 2010). They next followed mineral deposition in the caudal fin of the zebrafish larva by employing fluorescence and cryoscanning electron microscopy on transgenic zebrafish lines. This enabled them to detect mineral particles located between bones and in close association with blood vessels (Akiva et al., 2015). Their observations challenge the view that mineral formation is restricted to osteoblast cells juxtaposed to bone, or to the extracellular matrix. This combination of the unique methododologies used by Addadi and Weiner and their live imaging of transgenic zebrafish has contributed a new perspective to the comprehensive mechanism of bone mineralization in vertebrates.

\section{Muscular and bone pathology}

Alon Daya at the Ruppin Academic Center's School of Marine Sciences in Michmoret is working with Stella Mitrani-Rosenbaum from the Hebrew University of Jerusalem to study a specific human inherited myopathy. This unique, adult-onset neuromuscular disease is caused by mutations in the GNE gene that codes for a central enzyme in the biosynthesis of sialic acid. In studying the role of this disease-associated gene in muscle morphology and function, Daya and Mitrani-Rosenbaum have demonstrated a critical novel role for gne in embryonic development, and particularly in myofiber development, muscle integrity, and activity (Daya et al., 2014). Currently, the lab is establishing a zebrafish disease model that mimics mutations associated with human GNE myopathy in order to elucidate the pathogenesis of GNE myopathy and facilitate future screening and evaluation of potential therapeutics.

David Karasik at the Bar-Ilan University School of Medicine in the Galilee, Zefat, has recently begun using zebrafish to study the genetic basis of osteoporosis and the risk of bone fractures, and in particular the interaction between bone and muscle. He utilizes the zebrafish to study the function of genes linked in genome-wide association epidemiological studies with the risk of fractures.

\section{Gene regulation and $\mathrm{RNA}$ editing}

Ramon Birnbaum at Ben-Gurion University of the Negev is focusing on gene regulation of brain and fin/limb development and their association with neurodevelopmental disorders. Using a sequencing-based technology with functional assays in zebrafish and mouse, Birnbaum has described the gene regulatory networks underlying tissue specificity (Birnbaum et al., 2012b). Essentially, the Birnbaum lab utilizes zebrafish for in-vivo enhancer screening and to manipulate developmental genes and their regulatory elements in the zebrafish genome. Their current projects involve functional genomic characterization of the gene-regulatory elements associated with epilepsy, focusing on disease-associated mutations in genes expressed in the developing forebrain (e.g. FOXG1). The ultimate goal is to reveal the role of epilepsyassociated genes, and to highlight novel genomic regions that could be involved in both brain development and the pathogenesis of epilepsy. Birnbaum is also studying the dual function of DNA sequences as coding exons and transcriptional enhancers. By 
analyzing enhancer-associated ChIP-seq datasets Birnbaum found that, on average, $6 \%$ of peaks overlap coding exons, suggesting that numerous exonic-enhancers (eExons) are embedded in mammalian genomes (Birnbaum et al., 2012a). Using zebrafish, his lab demonstrated that coding exons could function as enhancers of nearby genes (Zhang et al., 2013).

Gideon Rechavi, who heads the Cancer Research Center of the Sheba Medical Center at Tel Hashomer, is using zebrafish to study global RNA editing and its role in brain development, neuronal functions, and cancer. Previous work, which was part of Erez Levanon's PhD thesis, focused on the role of RNA editing in basic cellular regulatory activities and the causal relation between abnormal editing and a variety of disease states in humans (Levanon et al., 2004). After Levanon established his own lab at Bar-Ilan University he teamed up with Lior Appelbaum. The two groups have identified thousands of clustered RNA editing sites in the zebrafish transcriptome, and correlated altered RNA editing with neurological deficiencies in a zebrafish model for FXS (Shamay-Ramot et al., 2015).

\section{Aquaculture}

Aquaculture in Israel is a continuously growing and expanding industry that has derived ongoing benefit from the highly educated manpower and the close relationships between growers and research institutions. Many fish species have been introduced into the Israeli aquaculture industry, and attempts to increase profitability and overcome bottlenecks in production spurred research and development in the fields of fish reproduction, development and growth, genetics, nutrition, and disease. The advantages of zebrafish as a tool have not escaped the attention of Israeli aquacultural researchers, and this fish has been increasingly used as a model for the biology of fish in general.

Research on the hypothalamic regulation of gonadotropins and the development of the $\mathrm{GnRH}$ system in zebrafish by Yoav Gothilf and Berta Levavi-Sivan, in collaboration with Yonatan Zohar, University of Maryland, has been driven in part by the need to control reproduction in commercial species, enabling them to complete their life cycle in captivity on the one hand and blocking their sexual maturation so as to allow genetic containment and promote muscle growth on the other. A major bottleneck in fish farming is the development and survival of offspring, which largely depends on the nutritional quality of the yolk and its composition. Esther Lubzens and her group at the Israel Oceanographic and Limnological Research Institute (IOLR) in Haifa have been studying the biosynthesis of vitellogenin and retinal and their incorporation into the yolk in zebrafish (Levi et al., 2009, Levi et al., 2012). Bruria Funkenstein at the IOLR has been utilizing zebrafish to study the differentiation and growth of fish skeletal muscle, with obvious links to the needs of the fish-farming industry. A major focus of this group is the transcription factor myostatin, a negative regulator of muscle growth (Funkenstein and Olekh, 2010).

The largest operating cost in fish farming is the high protein content of the feed requirements of fish. The main reasons for this cost are inefficient digestion and wasted (uneaten) feed, which affect profitability and generate environmental pollution. International efforts are now being made to increase feed utilization in aquaculture. Owing to differences in their natural diets, each farmed species constitutes a research topic of its own. Nonethe- less, work has been carried out using the zebrafish as a model. Bill Koven at the National Center for Mariculture in Eilat, together with newly-recruited researcher Amir Bitan, has been studying early effects of nutritional programming on feed consumption and finding ways to increase protein absorption and utilization. Focusing on the oligopeptide transporter PepT1, these scientists found that the expression of PepT1 is highly dependent on the state of feeding: it drops upon starvation and increases upon feeding (Koven and Schulte, 2012). The group, in collaboration with the Levkowitz group, is currently generating PepT1-mutant zebrafish lines, alongside a screening effort for functional feed additives that can elevate PepT1 expression and increase protein utilization in fish. Likewise, efforts made by Gothilf, Levavi-Sivan and Harpaz, in collaboration with Roger cone, University of Michigan, to manipulate the melanocortin system are aimed at increasing fish appetite and food utilization.

Given the accelerarting rate of human population growth, the high protein content and nutritional value of fish, and the current depletion of marine fisheries, the high demand for farmed fish will inevitably increase (FAO, 2014). Consequently, investments in aquacultural technologies in Israel, either by focusing on specific species or by using the zebrafish as a model, will clearly benefit the aquaculture industry worldwide.

\section{A bit of future}

Utilization of the zebrafish as a research model is exponentially increasing worldwide, and zebrafish research in Israel is expanding into the future. An increasing number of Israeli graduates are undergoing their postdoctoral training in leading zebrafish laboratories abroad, with the intent of returning to Israel to establish their own independent zebrafish research groups. Moreover, the ability to identify disease-associated human genes, along with the amenability of zebrafish to drug screening, is attracting a number of biomedical companies that may well join this research community over the coming years.

Zebrafish could also serve as a platform from which clinicians, geneticists and researchers can cooperate in the goal of identifying and studying disease-causing genetic variants in patients with undiagnosed genetic diseases, including rare diseases, thereby making progress towards patient treatment and disease prevention. High-throughput exome/genome sequencing, together with emerging bioinformatic tools, will provide an ever-expanding list of candidate genetic variants that warrant biological validation.

With an agenda to promote the zebrafish as a biomedical model organism, the establishment of a National Zebrafish Center is currently under discussion. The establishment of such a national infrastructure in Israel will make it possible to broaden studies utilizing this model at a competitive level, increase collaborations at the national and international levels, and support the activities and participation of biomedical companies. Finally, the planned Center has the potential to enhance the recruitment of additional zebrafish researchers to the Israeli academic community.

\section{Acknowledgements}

We thank Benny Geiger and Anat Yarden for sharing their story of the early zebrafish days in Israel; members of the Israeli zebrafish community who provided information about their current studies; Sandra Britton for comments on the manuscript; and Naomi Paz and Shirely Smith for their editorial work. G.L. is an incumbent of the Elias Sourasky Professorial Chair. 


\section{References}

ABRAHAM, E., PALEVITCH, O., GOTHILF, Y. and ZOHAR, Y. (2009). The zebrafish as a model system for forebrain GnRH neuronal development. Gen Comp Endocrinol 164: 151-160.

ABRAHAM, E., PALEVITCH, O., GOTHILF, Y. and ZOHAR, Y. (2010). Targeted gonadotropin-releasing hormone-3 neuron ablation in zebrafish: effects on neurogenesis, neuronal migration, and reproduction. Endocrinology 151: 332-340.

ABRAHAM, E., PALEVITCH, O., IJIRI, S., DU, S.J., GOTHILF, Y. and ZOHAR, Y. (2008). Early development of forebrain gonadotrophin-releasing hormone $(\mathrm{GnRH})$ neurones and the role of $\mathrm{GnRH}$ as an autocrine migration factor. J Neuroendocrinol 20: 394-405.

AKIVA, A., MALKINSON, G., MASIC, A., KERSCHNITZKI, M., BENNET, M., FRATZL, P., ADDADI, L., WEINER, S. and YANIV, K. (2015). On the pathway of mineral deposition in larval zebrafish caudal fin bone. Bone 75: 192-200.

ALON, S., EISENBERG, E., JACOB-HIRSCH, J., RECHAVI, G., VATINE, G., TOYAMA, R., COON, S.L., KLEIN, D.C. and GOTHILF, Y. (2009). A new cisacting regulatory element driving gene expression in the zebrafish pineal gland. Bioinformatics 25: 559-562.

AMIR-ZILBERSTEIN, L., BLECHMAN, J., SZTAINBERG, Y., NORTON, W.H., REUVENY, A., BORODOVSKY, N., TAHOR, M., BONKOWSKY, J.L., BALLY-CUIF, L., CHEN, A. et al., (2012). Homeodomain protein otp and activity-dependent splicing modulate neuronal adaptation to stress. Neuron 73: 279-291.

APPELBAUM, L., ANZULOVICH, A., BALER, R. and GOTHILF, Y. (2005). Homeoboxclock protein interaction in zebrafish. A shared mechanism for pineal-specific and circadian gene expression. J Biol Chem 280: 11544-11551.

APPELBAUM, L. and GOTHILF, Y. (2006). Mechanism of pineal-specific gene expression: the role of E-box and photoreceptor conserved elements. Mol Cell Endocrinol 252: 27-33.

APPELBAUM, L., TOYAMA, R., DAWID, I.B., KLEIN, D.C., BALER, R. and GOTHILF, Y. (2004). Zebrafish serotonin- $\mathrm{N}$-acetyltransferase-2 gene regulation: pinealrestrictive downstream module contains a functional $\mathrm{E}$-box and three photoreceptor conserved elements. Mol Endocrinol 18: 1210-1221.

APPELBAUM, L., WANG, G., YOKOGAWA, T., SKARIAH, G.M., SMITH, S.J., MOURRAIN, P. and MIGNOT, E. (2010). Circadian and homeostatic regulation of structural synaptic plasticity in hypocretin neurons. Neuron 68: 87-98.

AVRAHAM-DAVIDI, I., ELY, Y., PHAM, V.N., CASTRANOVA, D., GRUNSPAN, M., MALKINSON, G., GIBBS-BAR, L., MAYSELESS, O., ALLMOG, G., LO, B. et al., (2012). ApoB-containing lipoproteins regulate angiogenesis by modulating expression of VEGF receptor 1. Nat Med 18: 967-973.

AVRAHAM-DAVIDI, I., GRUNSPAN, M. and YANIV, K. (2013). Lipid signaling in the endothelium. Exp Cell Res 319: 1298-1305.

BASSI, I., V, A.N., MARELLI, F., VEZZOLI, V., MERLO, G.R., CARIBONI, A., PERSANI, L., GOTHILF, Y. and BONOMI, M. (2016). The zebrafish: an emerging animal model for investigating the hypothalamic regulation of reproduction. Minerva Endocrinol 41: 250-265.

BEN-MOSHE Z, LIVNE Z, ALON S, VALLONE D, BAYLEYEN Y, TOVIN A, SHAINER I, NISEMBAUM LG, AVIRAM I, SMADJA-STORZ S, FUENTES M, FALCÓN J, EISENBERG E, KLEIN DC, BURGESS HA, FOULKES NS, GOTHILF Y (2016). Genetically Blocking the Zebrafish Pineal Clock Affects Circadian Behavior. PLoS Genet. 21;12(11):e1006445.

BEN-MOSHE, Z., ALON, S., MRACEK, P., FAIGENBLOOM, L., TOVIN, A., VATINE, G.D., EISENBERG, E., FOULKES, N.S. and GOTHILF, Y. (2014a). The lightinduced transcriptome of the zebrafish pineal gland reveals complex regulation of the circadian clockwork by light. Nucleic Acids Res 42: 3750-3767.

BEN-MOSHE, Z., FOULKES, N.S. and GOTHILF, Y. (2014b). Functional development of the circadian clock in the zebrafish pineal gland. Biomed Res Int 2014: 235781.

BIRAN, J., TAHOR, M., WIRCER, E. and LEVKOWITZ, G. (2015). Role of developmental factors in hypothalamic function. Front Neuroanat 9: 47.

BIRNBAUM, R.Y., CLOWNEY, E.J., AGAMY, O., KIM, M.J., ZHAO, J., YAMANAKA, T., PAPPALARDO, Z., CLARKE, S.L., WENGER, A.M., NGUYEN, L. et al., (2012a). Coding exons function as tissue-specific enhancers of nearby genes. Genome Res 22: 1059-1068.

BIRNBAUM, R.Y., EVERMAN, D.B., MURPHY, K.K., GURRIERI, F., SCHWARTZ, C.E. and AHITUV, N. (2012b). Functional characterization of tissue-specific enhancers in the DLX5/6 locus. Hum Mol Genet 21: 4930-4938.
BITZUR, S., KAM, Z. and GEIGER, B. (1994). Structure and distribution of N-cadherin in developing zebrafish embryos: Morphogenetic effects of ectopic over-expression. Dev. Dyn. 201: 121-136.

BLECHMAN, J., AMIR-ZILBERSTEIN, L., GUTNICK, A., BEN-DOR, S. and LEVKOWITZ, G. (2011). The metabolic regulator PGC-1alpha directly controls the expression of the hypothalamic neuropeptide oxytocin. J Neurosci 31: 14835-14840.

BLECHMAN, J., BORODOVSKY, N., EISENBERG, M., NABEL-ROSEN, H., GRIMM, J. and LEVKOWITZ, G. (2007). Specification of hypothalamic neurons by dual regulation of the homeodomain protein Orthopedia. Development 134:4417-4426.

BLECHMAN, J. and LEVKOWITZ, G. (2013). Alternative Splicing of the Pituitary Adenylate Cyclase-Activating Polypeptide Receptor PAC1: Mechanisms of Fine Tuning of Brain Activity. Front Endocrinol (Lausanne) 4: 55.

BORODOVSKY, N., PONOMARYOV, T., FRENKEL, S. and LEVKOWITZ, G. (2009). Neural protein Olig2 acts upstream of the transcriptional regulator Sim1 to specify diencephalic dopaminergic neurons. Dev Dyn 238: 826-834.

DAYA, A., VATINE, G.D., BECKER-COHEN, M., TAL-GOLDBERG, T., FRIEDMANN, A., GOTHILF, Y., DU, S.J. and MITRANI-ROSENBAUM, S. (2014). Gne depletion during zebrafish development impairs skeletal muscle structure and function. Hum Mol Genet 23: 3349-3361.

DHAKAL, S., STEVENS, C.B., SEBBAGH, M., WEISS, O., FREY, R.A., ADAMSON, S., SHELDEN, E.A., INBAL, A. and STENKAMP, D.L. (2015). Abnormal retinal development in Cloche mutant zebrafish. Dev Dyn 244: 1439-1455

DRESNER, E., MALISHKEVICH, A., ARVIV, C., LEIBMAN BARAK, S., ALON, S. OFIR, R., GOTHILF, Y. and GOZES, I. (2012). Novel evolutionary-conserved role for the activity-dependent neuroprotective protein (ADNP) family that is important for erythropoiesis. J Biol Chem 287: 40173-40185.

DRIEVER, W., SOLNICA-KREZEL, L., SCHIER, A.F., NEUHAUSS, S.C., MALICKI, J., STEMPLE, D.L., STAINIER, D.Y., ZWARTKRUIS, F., ABDELILAH, S., RANGINI, Z. et al., (1996). Agenetic screen for mutations affecting embryogenesis in zebrafish. Development 123: 37-46.

ELBAZ, I., FOULKES, N.S., GOTHILF, Y. and APPELBAUM, L. (2013). Circadian clocks, rhythmic synaptic plasticity and the sleep-wake cycle in zebrafish. Front Neural Circuits 7: 9 .

ELBAZ, I., LERER-GOLDSHTEIN, T., OKAMOTO, H. and APPELBAUM, L. (2015) Reduced synaptic density and deficient locomotor response in neuronal activityregulated pentraxin 2a mutant zebrafish. FASEB J 29: 1220-1234.

ELBAZ, I., YELIN-BEKERMAN, L., NICENBOIM, J., VATINE, G. and APPELBAUM, L. (2012). Genetic ablation of hypocretin neurons alters behavioral state transitions in zebrafish. J Neurosci 32: 12961-12972.

FAO. (2014). The state of the world fisheries and aquaculture. FAO Rome.

FUNKENSTEIN, B. and OLEKH, E. (2010). Growth/differentiation factor-11: an evolutionary conserved growth factor in vertebrates. Dev Genes Evol 220: 129-137.

GOLAN, M., BIRAN, J. and LEVAVI-SIVAN, B. (2014). A novel model for development, organization and function of gonadotropes in fish pituitary. Frontiers in Endocrinology 5: 182.

GOLAN, M., MARTIN, A.O., MOLLARD, P. and LEVAVI-SIVAN, B. (2016). Anatomical and functional gonadotrope networks in the teleost pituitary. Sci Rep 6: 23777.

GOLAN, M., ZELINGER, E., ZOHAR, Y. and LEVAVI-SIVAN, B. (2015). Architecture of GnRH-Gonadotrope-Vasculature Reveals a Dual Mode of Gonadotropin Regulation in Fish. Endocrinology 156: 4163-4173.

GOTHILF, Y., TOYAMA, R., COON, S.L., DU, S.J., DAWID, I.B. and KLEIN, D.C. (2002). Pineal-specific expression of green fluorescent protein under the control of the serotonin- $\mathrm{N}$-acetyltransferase gene regulatory regions in transgenic zebrafish. Dev Dyn 225: 241-249.

GRUNWALD, D.J. and EISEN, J.S. (2002). Headwaters of the zebrafish -- emergence of a new model vertebrate. Nat Rev Genet 3: 717-724.

GUTNICK, A., BLECHMAN, J., KASLIN, J., HERWIG, L., BELTING, H.G., AFFOLTER, M., BONKOWSKY, J.L. and LEVKOWITZ, G. (2011). The hypothalamic neuropeptide oxytocin is required for formation of the neurovascular interface of the pituitary. Dev. Cell 21: 642-654.

GUTNICK, A. and LEVKOWITZ, G. (2012). The neurohypophysis: fishing for new insights. J. Neuroendocrinol. 24: 973-974.

HAFFTER, P., GRANATO, M., BRAND, M., MULLINS, M.C., HAMMERSCHMIDT, M., KANE, D.A., ODENTHAL, J., VAN EEDEN, F.J., JIANG, Y.J., HEISENBERG, C.P. et al., (1996). The identification of genes with unique and essential functions in the development of the zebrafish, Danio rerio. Development 123: 1-36. 
HEN, G., NICENBOIM, J., MAYSELESS, O., ASAF, L., SHIN, M., BUSOLIN, G., HOFI, R., ALMOG, G., TISO, N., LAWSON, N.D. et al., (2015). Venous-derived angioblasts generate organ-specific vessels during zebrafish embryonic development. Development 142: 4266-4278.

KAUFMAN, R., WEISS, O., SEBBAGH, M., RAVID, R., GIBBS-BAR, L., YANIV, K. and INBAL, A. (2015). Development and origins of zebrafish ocular vasculature. BMC Dev Biol 15: 18

KOVEN, W. and SCHULTE, P. (2012). The effect of fasting and refeeding on mRNA expression of PepT1 and gastrointestinal hormones regulating digestion and food intake in zebrafish (Danio rerio). Fish Physiol Biochem 38: 1565-1575.

LEVANON, E.Y., EISENBERG, E., YELIN, R., NEMZER, S., HALLEGGER, M., SHEMESH, R., FLIGELMAN, Z.Y., SHOSHAN, A., POLLOCK, S.R., SZTYBEL, D. et al., (2004). Systematic identification of abundant A-to-l editing sites in the human transcriptome. Nat Biotechnol 22: 1001-1005.

LEVI, L., PEKARSKI, I., GUTMAN, E., FORTINA, P., HYSLOP, T., BIRAN, J., LEVAVI-SIVAN, B. and LUBZENS, E. (2009). Revealing genes associated with vitellogenesis in the liver of the zebrafish (Danio rerio) by transcriptome profiling. BMC Genomics 10: 141.

LEVI, L., ZIV, T., ADMON, A., LEVAVI-SIVAN, B. and LUBZENS, E. (2012). Insight into molecular pathways of retinal metabolism, associated with vitellogenesis in zebrafish. Am J Physiol Endocrinol Metab 302: E626-E644.

LEVITAS-DJERBI, T., YELIN-BEKERMAN, L., LERER-GOLDSHTEIN, T. and APPELBAUM, L. (2015). Hypothalamic leptin-neurotensin-hypocretin neuronal networks in zebrafish. J Comp Neurol 523: 831-848.

LEVKOWITZ, G., ZELLER, J., SIROTKIN, H.I., FRENCH, D., SCHILBACH, S., HASHIMOTO, H., HIBI, M., TALBOT, W.S. and ROSENTHAL, A. (2003). Zinc finger protein too few controls the development of monoaminergic neurons. Nat Neurosci 6: 28-33.

MAHAMID, J., AICHMAYER, B., SHIMONI, E., ZIBLAT, R., LI, C., SIEGEL, S., PARIS, O., FRATZL, P., WEINER, S. and ADDADI, L. (2010). Mapping amorphous calcium phosphate transformation into crystalline mineral from the cell to the bone in zebrafish fin rays. Proc Natl Acad Sci USA 107: 6316-6321.

MAHAMID, J., SHARIR, A., ADDADI, L. and WEINER, S. (2008). Amorphous calcium phosphate is a major component of the forming fin bones of zebrafish: Indications for an amorphous precursor phase. Proc Natl Acad Sci USA 105: 12748-12753.

NICENBOIM, J., MALKINSON, G., LUPO, T., ASAF, L., SELA, Y., MAYSELESS, O., GIBBS-BAR, L., SENDEROVICH, N., HASHIMSHONY, T., SHIN, M. et al., (2015). Lymphatic vessels arise from specialized angioblasts within a venous niche. Nature 522: 56-61.

PALEVITCH, O., ABRAHAM, E., BORODOVSKY, N., LEVKOWITZ, G., ZOHAR, Y. and GOTHILF, Y. (2009). Nasal embryonic LHRH factor plays a role in the developmental migration and projection of gonadotropin-releasing hormone 3 neurons in zebrafish. Dev Dyn 238: 66-75.

PALEVITCH, O., ABRAHAM, E., BORODOVSKY, N., LEVKOWITZ, G., ZOHAR, Y. and GOTHILF, Y. (2010). Cxcl12a-Cxcr4b signaling is important for proper development of the forebrain GnRH system in zebrafish. Gen Comp Endocrinol 165: 262-268.

PALEVITCH, O., KIGHT, K., ABRAHAM, E., WRAY, S., ZOHAR, Y. and GOTHILF, Y. (2007). Ontogeny of the GnRH systems in zebrafish brain: in situ hybridization and promoter-reporter expression analyses in intact animals. Cell Tissue Res 327: 313-322.

RAINY, N., ETZION, T., ALON, S., POMERANZ, A., NISGAV, Y., LIVNAT, T., BACH, M., GERSTNER, C.D., BAEHR, W., GOTHILF, Y. et al., (2016). Knockdown of unc $119 \mathrm{c}$ results in visual impairment and early-onset retinal dystrophy in zebrafish. Biochem Biophys Res Commun 473: 1211-1217.

RUSSEK-BLUM, N., GUTNICK, A., NABEL-ROSEN, H., BLECHMAN, J., STAUDT, N., DORSKY, R.I., HOUART, C. and LEVKOWITZ, G. (2008). Dopaminergic neuronal cluster size is determined during early forebrain patterning. Development 135: 3401-3413.

RUSSEK-BLUM, N., NABEL-ROSEN, H. and LEVKOWITZ, G. (2009). High resolution fate map of the zebrafish diencephalon. Dev Dyn 238: 1827-1835.

SAMUEL, A., RUBINSTEIN, A.M., AZAR, T.T., BEN-MOSHE LIVNE, Z., KIM, S.H. and INBAL, A. (2016). Six3 regulates optic nerve development via multiple mechanisms. Sci Rep 6: 20267.

SEMO, J., NICENBOIM, J. and YANIV, K. (2016). Development of the lymphatic system: new questions and paradigms. Development 143: 924-935.

SHAINER I, BUCHSHTAB A, HAWKINS TA, WILSON SW, CONE RD, GOTHILF Y (2017). Novel hypophysiotropic AgRP2 neurons and pineal cells revealed by BAC transgenesis in zebrafish. Sci Reports 7: 44777

SHAMAY-RAMOT, A., KHERMESH, K., PORATH, H.T., BARAK, M., PINTO, Y, WACHTEL, C., ZILBERBERG, A., LERER-GOLDSHTEIN, T., EFRONI, S., LEVANON, E.Y. et al., (2015). Fmrp Interacts with Adar and Regulates RNA Editing, Synaptic Density and Locomotor Activity in Zebrafish. PLoS Genet 11: e1005702.

STIEBEL-KALISH, H., REICH, E., RAINY, N., VATINE, G., NISGAV, Y., TOVAR, A., GOTHILF, Y. and BACH, M. (2012). Gucy2f zebrafish knockdown--a model for Gucy2d-related leber congenital amaurosis. Eur J Hum Genet 20: 884-889.

STREISINGER, G., WALKER, C., DOWER, N., KNAUBER, D. and SINGER, F. (1981). Production of clones of homozygous diploid zebra fish (Brachydanio rerio). Nature 291: 293-296.

TOVIN, A., ALON, S., BEN-MOSHE, Z., MRACEK, P., VATINE, G., FOULKES, N.S., JACOB-HIRSCH, J., RECHAVI, G., TOYAMA, R., COON, S.L. et al., (2012) Systematic identification of rhythmic genes reveals camk1gb as a new element in the circadian clockwork. PLoS Genet 8: e1003116.

VATINE, G.D., ZADA, D., LERER-GOLDSHTEIN, T., TOVIN, A., MALKINSON, G., YANIV, K. and APPELBAUM, L. (2013). Zebrafish as a model for monocarboxyl transporter 8-deficiency. J Biol Chem 288: 169-180.

WEISS, O., KAUFMAN, R., MICHAELI, N. and INBAL, A. (2012). Abnormal vasculature interferes with optic fissure closure in Imo2 mutant zebrafish embryos. Dev Biol 369: 191-198.

WIRCER, E., BLECHMAN, J., BORODOVSKY, N., TSOORY, M., NUNES, A.R., OLIVEIRA, R.F., AND LEVKOWITZ, G. (2017). Homeodomain protein Otp affects developmental neuropeptide switching in oxytocin neurons associated with a longterm effect on social behavior. eLife 6. DOI: http://dx.doi.org/10.7554/eLife.22170

WIRCER, E., BEN-DOR, S. and LEVKOWITZ, G. (2016). Non-Mammalian Models for Neurohypophysial Peptides. In Molecular Neuroendocrinology. John Wiley \& Sons, Ltd, pp. 301-328.

YARDEN, A. and GEIGER, B. (1996). Zebrafish cyclin E regulation during early embryogenesis. Dev Dyn 206: 1-11.

YARDEN, A., SALOMON, D. and GEIGER, B. (1995). Zebrafish cyclin D1 is differentially expressed during early embryogenesis. Biochimica et Biophysica Acta (BBA) - Gene Struc. Expr. 1264: 257-260.

YELIN-BEKERMAN, L., ELBAZ, I., DIBER, A., DAHARY, D., GIBBS-BAR, L., ALON, S., LERER-GOLDSHTEIN, T. and APPELBAUM, L. (2015). Hypocretin neuron-specific transcriptome profiling identifies the sleep modulator Kcnh4a. Elife 4: e08638.

ZADA, D., TOVIN, A., LERER-GOLDSHTEIN, T., VATINE, G.D. and APPELBAUM, L. (2014). Altered behavioral performance and live imaging of circuit-specific neural deficiencies in a zebrafish model for psychomotor retardation. PLOS Genet 10: e1004615.

ZAMIR, E., KAM, Z. and YARDEN, A. (1997). Transcription-dependent induction of G1 phase during the zebra fish midblastula transition. Molec. Cell. Biol. 17: 529-536.

ZHANG, Y., WONG, C.H., BIRNBAUM, R.Y., LI, G., FAVARO, R., NGAN, C.Y., LIM, J., TAI, E., POH, H.M., WONG, E. et al., (2013). Chromatin connectivity maps reveal dynamic promoter-enhancer long-range associations. Nature 504:306-310.

ZIV, L. and GOTHILF, Y. (2006). Circadian time-keeping during early stages of development. Proc Natl Acad Sci USA 103: 4146-4151.

ZIV, L., LEVKOVITZ, S., TOYAMA, R., FALCON, J. and GOTHILF, Y. (2005). Functional development of the zebrafish pineal gland: light-induced expression of period2 is required for onset of the circadian clock. J Neuroendocrinol 17: 314-320.

ZIV, L., MUTO, A., SCHOONHEIM, P.J., MEIJSING, S.H., STRASSER, D., INGRAHAM, H.A., SCHAAF, M.J., YAMAMOTO, K.R. and BAIER, H. (2013). An affective disorder in zebrafish with mutation of the glucocorticoid receptor. $\mathrm{Mol}$ Psychiatry 18: 681-691. 


\section{Further Related Reading, published previously in the Int. J. Dev. Biol.}

The involvement of three signal transduction pathways in botryllid ascidian astogeny, as revealed by expression patterns of representative genes

Amalia Rosner, Gilad Alfassi, Elizabeth Moiseeva, Guy Paz, Claudette Rabinowitz, Ziva Lapidot, Jacob Douek, Abraham Haim and Baruch Rinkevich

Int. J. Dev. Biol. (2014) 58: 677-692

From Agrobacterium to viral vectors: genome modification of plant cells by rare cutting restriction enzymes Ira Marton, Arik Honig, Ayelet Omid, Noam De Costa, Elena Marhevka, Barry Cohen, Amir Zuker and Alexander Vainstein Int. J. Dev. Biol. (2013) 57: 639-650

What Hydra can teach us about chemical ecology - how a simple, soft organism survives in a hostile aqueous environment Tamar Rachamim and Daniel Sher Int. J. Dev. Biol. (2012) 56: 605-611

Analysis of chemotaxis when the fraction of responsive cells is small - application to mammalian sperm guidance Anna Gakamsky, Edna Schechtman, S. Roy Caplan and Michael Eisenbach

Int. J. Dev. Biol. (2008) 52: 481-487

Mouse models to study inner ear development and hereditary hearing loss Lilach M. Friedman, Amiel A. Dror and Karen B. Avraham Int. J. Dev. Biol. (2007) 51: 609-631

The importance of the posterior midline region for axis initiation at early stages of the avian embryo

Oded Khaner

Int. J. Dev. Biol. (2007) 51: 131-137

Early stages of neural crest ontogeny: formation and regulation of cell delamination Chaya Kalcheim and Tal Burstyn-Cohen

Int. J. Dev. Biol. (2005) 49: 105-116

Allogeneic interactions in Hydractinia: is the transitory chimera beneficial? Sharon Gild, Uri Frank and Ofer Mokady

Int. J. Dev. Biol. (2003) 47: 433-438

High proliferation rate characterizes the site of axis formation in the avian blastula-stage embryo.

N Zahavi, V Reich and O Khaner

Int. J. Dev. Biol. (1998) 42: 95-98
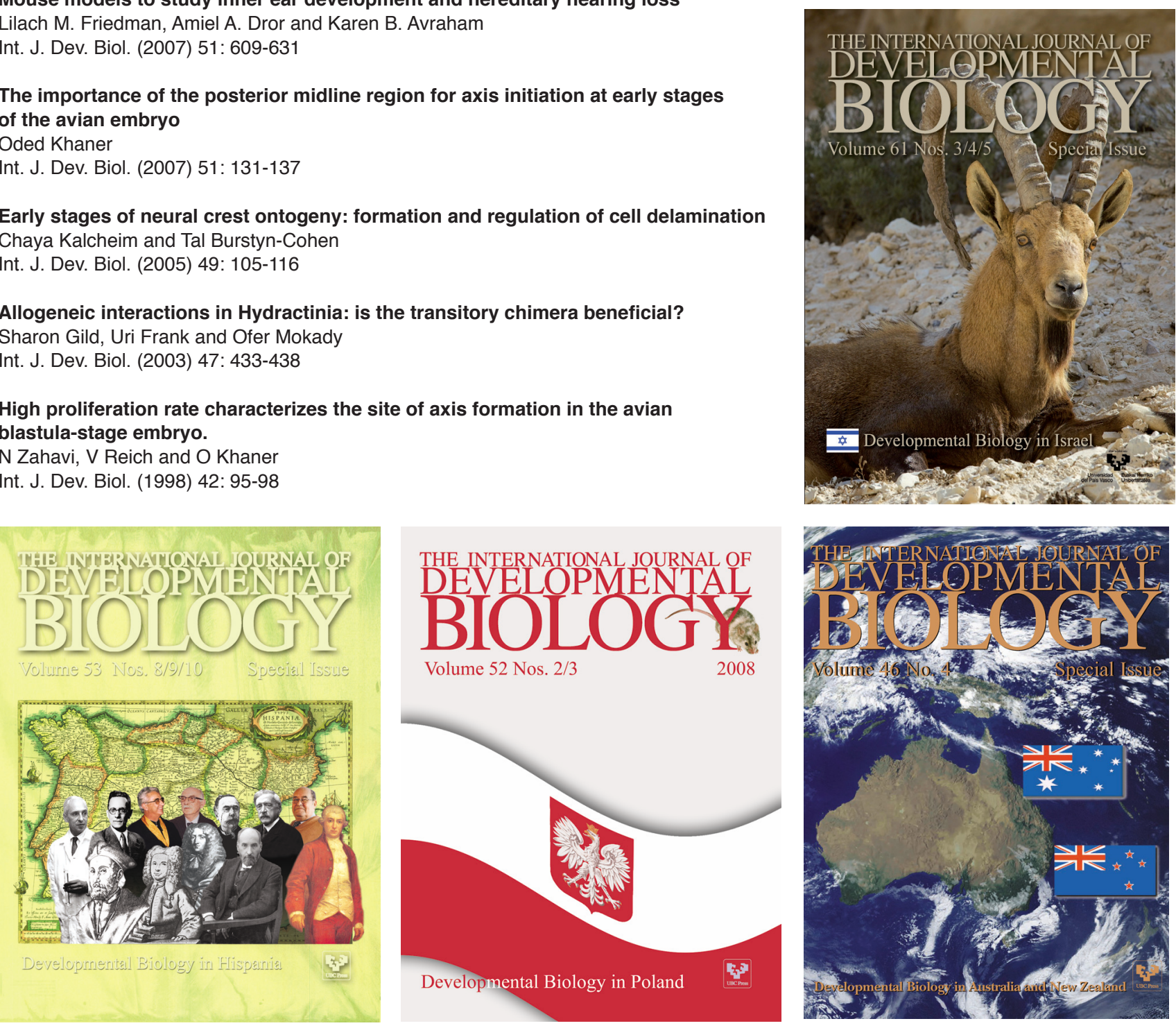